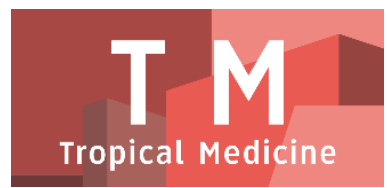

PAPER - OPEN ACCESS

\title{
Pengalaman Masyarakat Yang Menerima Pelayanan Perawat Puskesmas Sering Kecamatan Medan Tembung Sumatera Utara: Studi Fenomenologi
}

Author : Resi Ayu Harianti Harahap

DOI $\quad: 10.32734 /$ tm.v1i1.45

Paper Page : $94-98$

Volume 1 Issue 1 - 2018 TALENTA Conference Series: Tropical Medicine (TM)

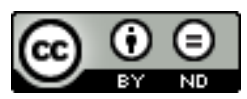

This work is licensed under a Creative Commons Attribution-NoDerivatives 4.0 International License.

Published under licence by TALENTA Publisher, Universitas Sumatera Utara
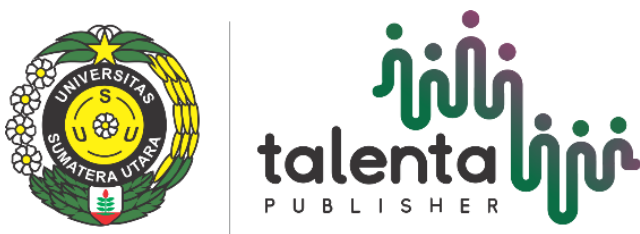


\title{
Pengalaman Masyarakat Yang Menerima Pelayanan Perawat Puskesmas Sering Kecamatan Medan Tembung Sumatera Utara: Studi Fenomenologi
}

\author{
Resi Ayu Harianti Harahapa ${ }^{a}$ Setiawan ${ }^{a}$ \\ ${ }^{a}$ Departemen Keperawatan, Fakultas Keperawatan, Universitas Sumatera Utara, Medan. 20155, Indonesia \\ resiharianti@yahoo.com, setiawan@usu.ac.id, setia-06@hotmail.com
}

\begin{abstract}
Abstrak
Puskesmas adalah salah satu fasilitas pelayanan kesehatan yang menyelenggarakan upaya kesehatan masyarakat tingkat pertama diwilayah kerjanya. Keperawatan merupakan salah satu bagian integral penting dari pelayanan kesehatan yang ada di puskesmas, diharapkan mampu memberikan pelayanan kesehatan yang meliputi aspek promotif dan preventif secara berkesinambungan tanpa mengabaikan pelayanan kuratif dan rehabilitaif secara menyeluruh dan terpadu kepada individu, keluarga, kelompok dan masyarakat. Penelitian ini bertujuan untuk mengeksplorasi pengalaman masyarakat tentang pelayanan perawat diPuskesmas Sering Kecamatan Medan Tembung. Penelitian ini menggunakan desain fenomenologi. Teknik pengambilan sampel yang digunakan adalah purposive sampling dengan jumlah partisipan sebanyak sepuluh orang. Data dianalisis menggunakan Content Analysis. Hasil penelitian didapatkan empat tema terkait pengalaman masyarakat yang menerima pelayanan perawat puskesmas Sering di Medan yaitu (1) menerima pelayanan kesehatan dari perawat puskesmas (2) menerima perilaku caring dan non-caring dari setiap pelayanan yang diberikan (3) mendapat penjelasan dan dimintai persetujuan sebelum tindakan diberikan (4) berpartisipasi dalam kegiatan pokok puskesmas. Penelitian ini merekomendasikan kepada puskesmas untuk mengevaluasi dan meningkatkan pelayanan kesehatan/keperawatan dengan mengetahui kelebihan dan kelemahan dalam pelayanan yang diberikan kepada masyarakat.
\end{abstract}

Kata Kunci: Pengalaman Masyarakat; Puskesmas; Pelayanan Perawat

\section{Pendahuluan}

Puskesmas merupakan sarana menyediakan pelayanan yang berkualitas, hemat biaya, peduli dalam melayani masyarakat serta puskesmas mampu dengan cepat, efisien, dan berhasil menargetkan layanan di area kerjanya [6]. Menurut Sumarji (2013) salah satu bentuk pelayanan Puskesmas membutuhkan tenaga kesehatan perawat dalam memberikan pelayanan keperawatan dengan menggunakan suatu pendekatan yaitu standar asuhan keperawatan. Dalam memberikan pelayanan tersebut perawat memberi kenyamanan dan rasa aman bagi klien, melindungi hak dan kewajiba klien agar tetap terlaksana dengan seimbang, memfasilitasi klien dengan anggota tim kesehatan lainnya serta berusaha mengembalikan kesehatan klien. Penelitian sebelumnya yang dilakukan oleh Badong (2005) tentang Analisa Tingkat Kepuasan Pasien Puskesmas di Kabupaten Donggala Sulawesi Tengah dapat memberikan gambaran bagaimana kepuasan yang diperoleh pasien puskesmas kabupaten Donggala belum memberikan tingkat kepuasan yang diinginkan oleh pasien karena belum mampu memenuhi harapan pasien. Penelitian juga dilakukan dipuskesmas Sumbersari Jember menunjukkan bahwa sebanyak 29 responden $(65,9 \%)$ menilai pelayanan perawat 
pada kategori kurang baik dan sebanyak 6 responden (34,1\%) menilai tidak baik [5]. Survey awal di Puskesmas Sering Tembung Medan diperoleh ternyata masyarakat terhadap pelayanan perawat Puskesmas Sering tidak jauh berbeda dari gambaran diatas. Masyarakat merasa pelayanan perawat Puskesmas Sering belum maksimal terutama dalam hal efektivitas waktu pelayanan perawat yang diberikan kepada masyarakat. Pelayanan perawat itu dapat diamati dari tindakan keperawatan yang diterima oleh masyarakat akan memunculkan suatu persepsi positif terhadap pelayanan. Sehingga image perawat di masyarakat memiliki tempat khusus di mata para pengguna jasa pelayanan kesehatan. Tujuan penelitian kualitatif ini adalah untuk mengeksplorasi pengalaman masyarakat tentang pelayanan perawat di Puskesmas Sering Kecamatan Medan Tembung dan manfaat nya diharapkan sebagai masukan dalam penentuan kebijakan oleh pihak yang dinas kesehatan dan puskesmas mengenai pelayanan perawat puskesmas mengenai pelayanan keperawatan yang diberikan.

\section{Metode}

Metode penelitian yang digunakan adalah desain penelitian dengan pendekatan fenomenologi. Lokasi yang penelitian yang digunakan di puskesmas Sering Kecamatan Medan Tembung. Penelitian ini dilakukan selama 3 bulan dan partisipan yang ikut serta dalam penelitian ini sebanyak 10 masyarakat dengan Pemilihan partisipan dalam penelitian ini menggunakan metode purposive sampling yaitu metode pemilihan partisipan dalam suatu penelitian dengan menentukan terlebih dahulu kriteria yang dimasukkan dalam penelitian [9].Data dikumpulkan dengan metode wawancara mendalam atau indepth-interview dengan waktu 25-60 menit dan direkan dengan dengan alat perekam. Hasil wawancara ditranskipkan kemudian dianalisis menggunakan menggunakan metode Giorgi [9] yaitu: rekaman hasil wawancara didengarkan dan diketik dalam bentuk transkrip. Peneliti memberikan nomor untuk setiap baris hasil transkrip (line). Kemudian peneliti membaca seluruh transkrip yang diperoleh dari rekaman wawancara, transkrip dibaca beberapa kali untuk memperoleh gambaran umum tentang seluruh pernyataanpernyataan partisipan. Selanjutnya peneliti menentukan pernyataan-pernyataan yang bermakna pada setiap transkrip, beberapa pernyataan yang mempunyai makna yang sama digabungkan menjadi satu kategori, sedangkan pernyataan yang berbeda dipertimbangkan untuk dijadikan sebagai kategori baru atau dihilangkan, selanjutnya peneliti mengelompokkan kategori yang saling berhubungan membentuk tema atau subtema. Kemudian peneliti membaca tema atau subtema yang telah diperoleh dan harus disesuaikan dengan tujuan penelitian. Terakhir mengintegrasikan dan mensintesis tema dan subtema kedalam deskripsi yang menyeluruh.

\section{Hasil}

Hasil penelitian ini mendapatkan 4 tema terkait pengalaman masyarakat yang menerima pelayanan perawat puskesmas Sering Kecamatan Tembung Kota Medan meliputi (1) menerima pelayanan kesehatan dari perawat puskesmas (2) menerima perilaku caring dan non-caring dari setiap pelayanan yang diberikan (3) mendapat penjelasan dan dimintai persetujuan sebelum tindakan diberikan (4) berpartisipasi dalam kegiatan pokok puskesmas.

\subsection{Menerima Pelayanan Kesehatan Dari Perawat Puskesmas}

Pelayanan yang didapatkan dari perawat puskesmas berupa pengkajian keperawatan mengenai riwayat kesehatan dengan ditanya keluhan dan gejala yang dirasakan, dikaji riwayat kesehatan sebelumnya , menjalankan pemeriksaan fisik dan pemeriksaan penunjang . dan pelayanan kesehatan yang kedua dari perawat puskesmas berupa intervensi keperawatan yang berupa pemberian injeksi dan Penkes (pendidikan kesehatan).

“ditanya tanyalah keluhan kita sakitnyaaa apa aja yang saya rasakan, sakitnya tuh masih tertahanka atau gak banyak lah ditanya dia tapi tanya tentang keluhan saya sih dek $\quad$ "(P1)

"mereka nanya tentang makanan atau pola hidup sebelum saya didiagnosa penyakit DM, dan pengobatanapa aja yg pernah saya lakukan, ya kayak gitu gitulahh” (P2)

“trus dikasih tau Tentang nutrisi bayi dan ibuk, asi nya itu harus lancar agar bayi nya gak lapar” (P9) 


\subsection{Menerima Perilaku Caring dan Non-caring Dari Setiap Pelayanan Yang Diberikan}

Perilaku caring yang digambarkan masyarakat saat mereka mendapatkan pelayanan kesehatan dari perawat puskesmas seperti menerima pelayanan yang ramah, mendapat kenyamanan dengan pelayan perawat dan mendapatkan perhatian dari pelayanan perawat

“kayaknya semua pasien gitu dek, sama beberapa pasien lah kutengok kek gitu dek disapa nya, kek sama cucu ku ramah kali dek, pande dia bagaimana menyapa dengan anak kecil”(P1)

“disitu saya jugak saya diperlakukan layaknya keluarga mereka yang jadi kalo saya berobat disana betah lah saya lama lama disana" (P2)

Perilaku non-caring yang diperlihatkan oleh perawat puskesmas saat memberikan pelayanan dipuskesmas ialah Waktu pelayanan untuk pasien yang masih kurang dan sikap cuek perawat pada saat situasi puskesmas ramai.

"iya cueknya kadang saya diacuhkan oleh perawatnya, karena mungkin saya agak banyak tanya, kan karena saya tidak mengerti, ya jadi saya banyak Tanya, tpi itupun saya dicuekin, diabaikan” ( P8)

paling yaaaaa masalah waktu yang Kadang kurang efektif lah gitu, misal nya ada penyuluhan tentang ibu hamil dan Menyusui gitu kan, waktu yang diberi tahu sama jadwal kegiatannya molor" (P9)

\subsection{Mendapatkan Penjelasan dan Dimintai Persetujuan Sebelum Tindakan Diberikan}

Pelayanan yang partisipan dapatkan dari perawat dipuskesmas seperti masyarakat mendapat penjelasan mengenai tindakan ketika tindakan akan dilakukan.

"pertama tama yang dijelaskannya itu Eh misalnya dulu nyuntik kan, dijelaskannya dibagian mana yang akan dilakukan penyuntikan, kemudian dijelaskan kannya agar apa dan untuk apanya jadi saya tau” (P6)

Partisipan juga dimintai persetujuan sebelum tindakan akan dilakukan sehingga perawat puskesmas dalam melakukan tindakan dan diketahui oleh masyarakat yang datang berobat.

“mereka melakukan tindakan yang sesuai dengan mereka katakan, meminta persetujuan terlebih dahulu hingga kami memberi persetujuan, sebelum melakukan tindakan sih itu dek ...” ( P5)

\subsection{Berpartisipasi Dalam Kegiatan Pokok Puskesmas}

Program kerja yang dilaksanakan oleh puskesmas terdapat 18 usaha pokok kesehatan yang dapat dilakukan. Kegiatan-kegiatan pokok tersebut dilakukan lansung oleh perawat puskesmas Sering melibatkan masyarakat untuk mengikuti kegiatan tersebut. Partisan juga mengatakan bahwa banyak kegiatan yang mereka diajak berpaertisipasi di puskesmas tersebut, seperti diajak untuk mengikuti senam dan kegiatan kesehatan lingkungan dan berpartisipasi dalam megikuti kegiatan penyuluhan kesehatan.

“misalnya perawat mengajak untuk mengikuti senam pagi untuk kebugaran, saya mengikuti kegiatan tersebut , kegiatan rutin dipuskesmas" (P 5)

"Kadang acara PHBS itu nanti mereka mengajak pasien pasien disini untuk ikut membersihkan lingkungan Sekitar untuk mencegah penularan penyakit" (P9) 


\section{Pembahasan}

Hasil penelitan ini memperlihatkan bahwa perawat puskesmas juga berperan untuk memberikan pelayanan kesehatan berupa asuhan keperawatan secara langsung kepada klien (individu, keluarga, komunitas) sesuai dengan kewenangan perawat di puskesmas Sering terebut. Asuhan keperawatan merupakan proses atau rangkaian kegiatan praktik keperawatan langsung pada klien di berbagai tatanan pelayanan kesehatan yang pelaksanaannya berdasarkan kaidah profesi keperawatan dan merupakan inti praktik keperawatan [1]. Praktik keperawatan dipuskesmas itu sebagai tindakan keperawatan kepada masyarakat dalam memberikan pelayanan dan menggunakan berbagai ilmu dasar serta ilmu keperawatan sebagai landasan untuk melakukan pengkajian, menegakkan diagnosis, menyusun perencanaan, melaksanakn asuhan keperawatan, dan mengevaluasi hasil tindakan keperawatan serta mengadakan penyesuaian rencana keperawatan uuntuk menentukan tindakan selanjutnya. Namun pada penelitian ini pelayanan kesehatan yang diberikan hanya berupa pengkajian keperawatan dan intervensi keperawatan. Perawat puskesma Sering juga memberika pelayana caring kepada setiap masyarakat yang datang berobat, dengan memperlihatkan sikap yang baik dalam memberikan perhatian atau penghargaan kepada seorang manusia diartikan member bantuan kepada individu atau advokasi pada individu yang tidak mampu memenuhi kebutuhan dasarnya [8].

Pada penelitian ini terlihat juga tiga partisipan mengatakan bahwa perawat masih cuek terhadap pasien. Dimana perawat sering mengacuhkan saran atau keluhan yang dirasakan oleh partisipan. Sementara menurut Gespersz (Bustami, 2011), bahwa kualitas pelayanan perawat dapat diukur dari aspek Tanggung jawab, dimana aspek ini bekaitan dengan penanganan keluhan dan repon dari pasien. perawat bertangggung jawab dengan kondisi dan keluhan pasien, serta menerima segala respon dari masyarakat agar masyarakat merasa nyaman dengan pelayanan yang diberikan.

Informasi atau penjelasan merupakan hal yang sangat berefek setiap pelayanan keperawatan yang dilakukan, dan ini merupakan hal yang sangat penting untuk disampaikan kepada pasien atau keluarga yaitu informasi mengenai apa yang harus disampaikan, tentulah segala sesuatu yang berkaitan dengan penyakit pasien. Tindakan apa yang akan dilakukan tentunya prosedur tindakan yang akan dijalani baik diagnostik maupun terapi dan lain - lain sehingga pasien/keluarga dapat memahaminya dan memberikan persetujuan tulis maupun lisan, persetujuan diberikan setelah pasien mendapat informasi yang adekuat, cara penyampaian informasi disesuaikan dengan tingkat pendidikan serta kondisi dan situasi pasien, setiap tindakan yang mengandung risiko tinggi harus dengan persetujuan, selain itu dengan lisan. Sama halnya dengan hasil penelitian Priambodo (2014) juga menjelaskan bahwa tindakan perawat terhadap pasien dalam melakukan asuhan keperawatan bukan hanya $\backslash$ memberi salam, memperkenalkan diri, tetapi juga meminta persetujuan pasien setiap akan melakukan tindakan. Program kerja yang dilaksanakan oleh puskesmas juga terdapat beberapa kegiatan pokok kesehatan dan non pokok yang dapat dilakukan. Namun, pelaksanaannya sangat tergantung pada tenaga kesehatan, sarana dan prasarana, biaya yang tersedia, serta kemampuan manajemen. Salah satu tenaga kesehatan yang berperan untuk melakukan kegiatan tersebut ialah perawat. Dalam analisis pada penelitian ini menyebutkan bahwa kegiatan-kegiatan pokok dan nonpokok puskesmas banyak dilakukan oleh perawat puskesmas Sering dan melibatkan masyarakat untuk mengikuti kegiatan tersebut. Partisan juga mengatakan bahwa banyak kegiatan yang mereka diajak untuk ikut dan berpartisipasi dikegiatan puskesmas tersebut, seperti diajak mengikuti kegiatan senam rutin untuk para lansia, pasien DM dan masyarakat laiinya, kemudian diajak mengikuti kegiatan kesehatan lingkungan dan berpartisipasi dalam kegiatan peyuluhan kesehatan.

\section{Kesimpulan}

Berdasarkan hasil wawancara mendalam yang dilakukan terhadap sepuluh partisipan, maka penelitian ini menemukan ada 4 tema terkait pengalaman masyarakat yang menerima pelayanan perawat puskesmas sering kecamatan Medan Tembung, yaitu : (1) menerima pelayanan kesehatan dari perawat puskesmas (2) menerima perilaku yang caring dan non-caring dari setiap pelayanan yang diberikan (3) mendapat penjelasan dan dimintai persetujuan sebelum tindakan diberikan (4) berpartisipasi dalam kegiatan pokok puskesmas.Hasil penelitian dapat digunakan sebagai masukan dan informasi bagi untuk mengetahui pengalaman masyarakat yang menerima pelayanan perawat puskesmas Sering. Hasil penelitian ini dapat dijadikan sebagai masukan bagi puskasmas untuk 
mengevaluasi dan meningkatkan pelayanan kesehatan/keperawatan dengan mengetahui kelebihan dan kelemahan dalam pelayanan yang diberikan kepada masyarakat. Hasil penelitian ini dapat digunakan sebagai masukan atau referensi untuk penelitian kualitatif, dan yang ingin melakukan penelitian lebih lanjut terhadap pengalaman masyarakat tentang pelayanan perawat puskesmas se-kota Medan.

\section{Daftar Pustaka}

[1] Ali, Z. (2009). Pengantar Keperawatan Keluarga. Jakarta: EGC

[2] Badong, M. I. (2005). Analisa Tingkat Kepuasa Pasien Puskesmas di Kabupaten Donggala. Jurnal. Sulawesi: Forum Komunikasi Masyarakat Sulawesi Tengah Bandung

[3] Efendi, F.M. (2009). Keperawatan Kesehatan Komunitas : Teori dan Praktek dalam Keperawatan. Jakarta : Salemba Medika

[4] Darmadi. (2006). Visi Pengembangan Peran dan Fungsi Puskesmas dengan Rawat Inap di Masa Mendatang. Jurnal Manajemen Pelayanan Kesehatan Volume 1(1)

[5] Desimawati, D.W. (2013). Hubungan Layanan Keperawatan dengan Tingkat Kepuasan Pasien Rawat Inap di Puskesmas Sumbersari Kabupaten Jember. Skripsi. Program Studi Ilmu Keperawatan Universitas Jember

[6] Hawkins,D., \& Groves , DaShawn. (2011). The Future Role of Community Health Centers in a Changing Health Care Landscape. J Ambulatory Care Manage, Volume 34(1) 90-99

[7] Menteri Kesehatan Republik Indonesia. (2006). Keputusan Menteri Kesehatan Nomor: 279/MENKES/SK/IV/2006 tentang Pedoman Penyelenggaraan Upaya Keperawatan Kesehatan Masyarakat di Puskesmas. Jakarta: Menteri Kesehatan. Jakarta

[8] Nursalam, E. F. (2008). Pendidikan dalam Keperawatan. Jakarta: Salemba Medika

[9] Polit, D.F., \& Beck, C.T. (2012). Nursing Research: Generating and Assesing Evidence for Nursing Practice (9th ed). Philadelphia: Lippincott

[10] Potter, P.A., \& Perry, A.G. (2010). Fundamental Keperawatan. Edisi 7. Buku 1. Terjemahan. Salemba Medika: Jakarta

[11] Sumarji, D.W. (2013). Analis Motivasi Tenaga Keperawatan Dalam Menerapkan Asuhan Keperawatan di Puskesmas Rawat Inap Kabupaten Nganjuk. Jurnal Ilmu Manajemen, REVITALISASI, Vol. 2, No. 3 